\title{
Associations Between Objectively Measured Physical Activity, Body Composition and Sarcopenia: Findings from the Hertfordshire Sarcopenia Study (HSS)
}

\author{
Leo D. Westbury ${ }^{1} \cdot$ Richard M. Dodds $^{2}$ - Holly E. Syddall ${ }^{1}$ A Alicja M. Baczynska ${ }^{2,3,4} \cdot$ Sarah C. Shaw $^{1}$. \\ Elaine M. Dennison ${ }^{1} \cdot$ Helen C. Roberts ${ }^{2,3,4} \cdot$ Avan Aihie Sayer ${ }^{2,5,6}$. Cyrus Cooper ${ }^{1,7} \cdot$ Harnish P. Patel $^{1,2,3}$ (1)
}

Received: 28 January 2018 / Accepted: 16 March 2018 / Published online: 27 March 2018

(c) The Author(s) 2018

\begin{abstract}
Regular physical activity (PA) is associated with reduced risk of the development and progression of musculoskeletal, metabolic and vascular disease. However, PA declines with age and this can contribute to multiple adverse outcomes. The aims of this study were to describe the relationship between accelerometer-determined PA, body composition and sarcopenia (the loss of muscle mass and function with age). Seven-day PA was measured using the GENEactiv accelerometer among 32 men and 99 women aged 74-84 years who participated in the Hertfordshire Sarcopenia Study. We measured mean daily acceleration and minutes/day spent in non-sedentary and moderate-to-vigorous physical activity (MVPA) levels. Body composition was measured by dual-energy X-ray absorptiometry, muscle strength by grip dynamometry and function by gait speed. Sarcopenia was defined according to the EWGSOP diagnostic algorithm. Men and women spent a median (inter-quartile range) of $138.8(82,217)$ and $186(122,240)$ minutes/day engaging in non-sedentary activity but only $14.3(1.8,30.2)$ and $9.5(2.1,18.6) \mathrm{min}$ in MVPA, respectively. Higher levels of PA were associated with reduced adiposity, faster walking speed and decreased risk of sarcopenia. For example, a standard deviation (SD) increase in mean daily acceleration was associated with an increase in walking speed of 0.25 (95\% CI 0.05, 0.45) SDs and a reduction in the risk of sarcopenia of 35\% (95\% CI $1,57 \%$ ) in fully adjusted analyses. PA was not associated with hand grip strength. Community-dwelling older adults in this study were largely sedentary but there was evidence that higher levels of activity were associated with reduced adiposity and improved function. PA at all intensity levels in later life may help maintain physical function and protect against sarcopenia.
\end{abstract}

Keywords Objectively measured physical activity $\cdot$ Accelerometer $\cdot$ Body composition $\cdot$ Physical performance $\cdot$ Sarcopenia

\section{Introduction}

Sarcopenia is associated with a broad array of adverse physical, metabolic and health-related changes such as reduced mobility, falls, fractures, diabetes, poorer health-related quality of life and death [1,2]. Physical activity (PA) is defined as bodily movement produced by the bone/muscle unit that results in energy expenditure [3]. Engagement in regular PA such as walking, cycling, work-related activity,

Electronic supplementary material The online version of this article (https://doi.org/10.1007/s00223-018-0413-5) contains supplementary material, which is available to authorized users.

Harnish P. Patel

hp@mrc.soton.ac.uk

Extended author information available on the last page of the article sports, gym work, dancing or gardening has been associated with a reduction in the risk of development, or progression, of cardiovascular and cerebrovascular disease, type II diabetes, cognitive decline, obesity, falls and fractures [4-6]. Other benefits of regular physical activity include a greater sense of well-being and self-esteem [7].

However, physical inactivity and sedentary behaviour are common among older people which can lead to an acceleration in muscle catabolism as well as reduced aerobic capacity. In conjunction with other personal, social and environmental factors (such as access to food and social isolation), a decline in physical activity can create a spiral of further inactivity, muscle loss, weight gain, mobility disability and an increase in cardio-metabolic risk [8,9]. Therefore, measurement and monitoring of PA and improved understanding of its associations with health outcomes are important to inform public health policy. 
Objective measurement of physical activity with accelerometers has gained acceptance as a preferred method for the collection of data on the duration, frequency and intensity of activity [10] and is acceptable for large scale epidemiological studies in older people $[4,11]$. Several studies have explored the associations between objectively measured PA and measures of body composition and function [12-16]. For example, higher physical activity and low sedentary activity were associated with lower body mass index (BMI) in a cross-sectional analysis of the LIFE study [12]. Aggio et al. showed that in a cohort of 1286 older men aged 70-92, higher levels of MVPA were associated with reduced risk of sarcopenia as defined by the European Working Group on Sarcopenia in Older People (EWGSOP) but where low muscle mass was defined by lower mid-upper arm circumference (MUAC) [4]. In a study of 636 community-dwelling older men and women 59-73 years, Foong et al. showed that higher intensities of PA were associated with higher lean mass and stronger lower limb strength [11]. Associations between PA and better function have also been observed in older adults in assisted care facilities. For example, better accelerometer-based PA was associated with a better short physical performance battery (SPPB) score, grip strength and faster walk speed in older adults aged over 65 [17]. A recent meta-analysis of 25 studies by Steffl et al. concluded that PA, measured by self-report as well as with accelerometers, was associated with reduced odds of acquiring lower muscle mass or 'sarcopenia', in later life [18].

Therefore, our aim for this study was to explore the crosssectional associations between accelerometer derived PA in relation to body composition and sarcopenia as defined by the EWGSOP. This study benefits from the availability of both objectively measured PA and comprehensive characterisation of muscle mass and function by DXA, grip dynamometry and physical performance measures in healthy community-dwelling older men and women aged $74-84$ years.

\section{Methods}

\section{Participants}

The Hertfordshire Sarcopenia Study (HSS) is a retrospective cohort study designed to investigate life course influences on muscle morphology, mass and strength in community-dwelling older people. The first phase of the study focusing on men has previously been described in detail [19]. The second phase of the study (2012-2015) recruited both men and women, herein termed HSSe. Briefly, 1188 participants from the UK Hertfordshire Cohort Study (HCS) [20] were identified as the target sample for HSSe. Of these, 303 wished to participate in the study. All participants were contacted by telephone consecutively and the following clinical exclusion criteria were applied: concurrent use of anticoagulant medication, neuromuscular comorbidity or diabetes. One hundred and ninety-nine participants $(66 \%)$ were eligible, available and were willing to have a home visit by the research team. Of these, 18 participants were excluded at the time of the home visit due to concurrent medical conditions requiring follow-up and 12 declined to participate further. A total of 169 participants were scheduled to attend a research clinic, but one further participant was excluded at the time of clinical review. Overall, 44 men and 124 women had detailed assessments of body composition and muscle function (Fig. 1).

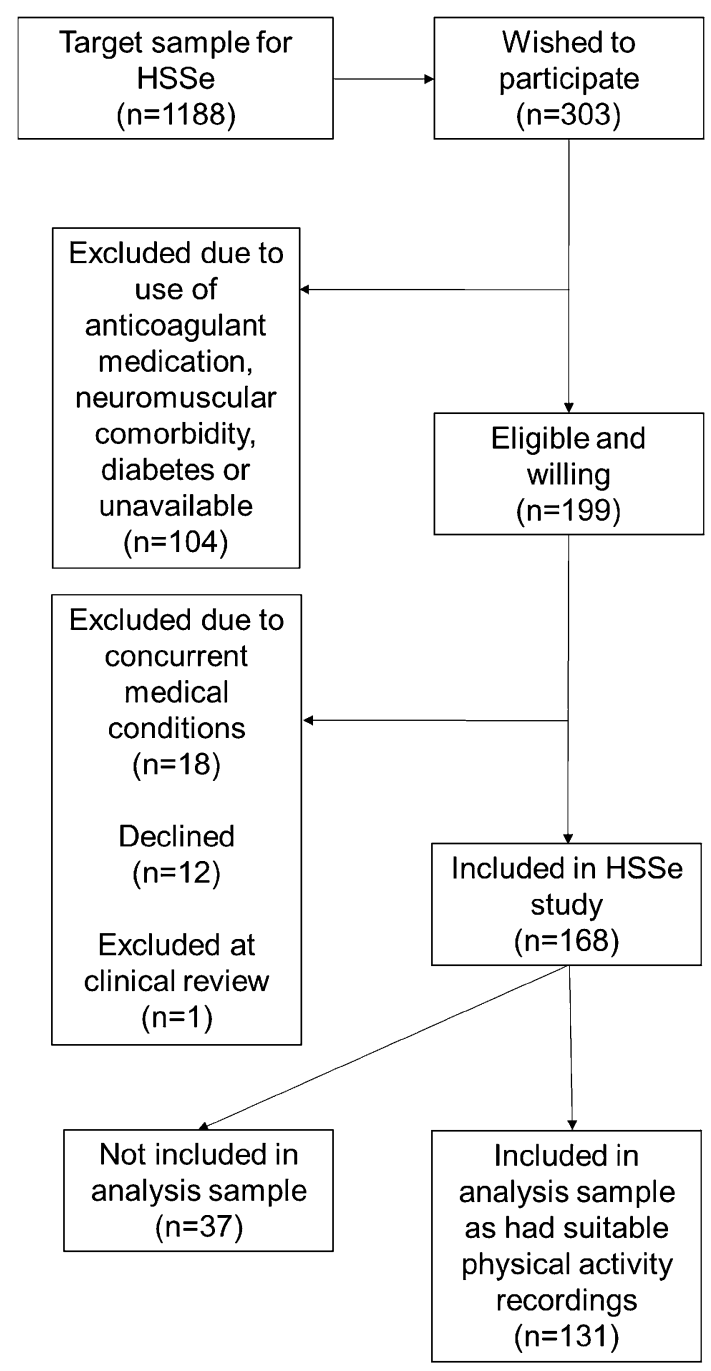

HSSe: Hertfordshire Sarcopenia Study

Fig. 1 Flow diagram for the analysis sample 


\section{Recording of Accelerometry Data}

At the time of the home visit, participants were asked to wear a GENEActiv (ActivInsights Ltd, Cambridgeshire, UK) accelerometer on the non-dominant wrist to objectively measure their physical activity. Given limited supply of the accelerometers, devices were activated and posted to participants in some instances. Recordings were made over a 7-day period after the participant started wearing the device. All devices were returned from participants by post. Thereafter, GENEActiv data were downloaded using GENEActiv PC software version 2.2 and saved in raw format as binary files. Accelerometer data were processed in R (http://www. cran.r-project.org) using R-package GGIR [21]. Recording frequencies of 100 and $25 \mathrm{~Hz}$ were used.

\section{Derivation of Objective Physical Activity Measures}

A detailed account of the processing of accelerometer data is presented in the supplementary pages online. For each participant, mean daily (over 24-h period) physical activity measures included overall acceleration in milli-g $(\mathrm{mg})$, daily time spent in MVPA ( $\geq 100 \mathrm{mg}$ ) and daily time spent in non-sedentary physical activity levels $(\geq 40 \mathrm{mg})$. The cut-off value for MVPA corresponds to approximately three metabolic equivalents (METs) for adults and has been used in other studies of community-dwelling older people [22, 23]. The range $0-40 \mathrm{mg}$ was chosen as the sedentary category in a previous study involving the use of the GENEActiv accelerometer in older people (average age 79 years) [24]. Overall, 30 participants (18\%) were excluded from the analysis for the following reasons: unable to contact; refusal to wear the device; technical problem with the accelerometer or excessive periods of non-wear detected in preliminary analysis. A total of 138 recordings were processed. Of these, two participants had recordings of less than 7 days; one had taken the device off to sleep; and four had unfeasible values and were excluded from analyses. Consequently, the analysis sample comprised 131 participants (32 men, 99 women) with objective physical activity recordings. A flow diagram for the analysis sample is provided in Fig. 1. There were no statistically significant differences regarding the outcome variables of interest between participants with and without suitable physical activity data.

\section{Measurement of Anthropometry, Physical Performance and Body Composition}

Height in centimetres $(\mathrm{cm})$ and weight in kilograms $(\mathrm{kg})$ were measured once. Body composition [total lean mass, appendicular lean mass (ALM), and fat mass] was assessed by dual-energy X-ray absorptiometry (DXA) (Hologic Discovery, software version 12.5 ) for all participants. Isometric grip strength $(\mathrm{kg})$ was measured three times in each hand using a Jamar handheld hydraulic dynamometer (Promedics, UK) and the maximum value of six measures was used for analysis. Customary walking speed was measured over a three-metre course. Both the DXA machine and dynamometer were calibrated before the study and at regular intervals throughout the study.

\section{Derivation of Sarcopenia Status}

Sarcopenia status at follow-up was derived using the EWGSOP diagnostic algorithm with the following cut-points: appendicular lean mass index (ALM/height $\left.{ }^{2}\right) \leq 7.23 \mathrm{~kg} / \mathrm{m}^{2}$ for men $\left(\leq 5.67 \mathrm{~kg} / \mathrm{m}^{2}\right.$ for women); grip strength $<30 \mathrm{~kg}$ for men $(<20 \mathrm{~kg}$ for women); and walking speed $\leq 0.8 \mathrm{~m} / \mathrm{s}$ [25]. Participants with slow walking speed or weak grip strength, and who also had low ALM index were classed as having sarcopenia.

\section{Ascertainment of Socio-demographic and Lifestyle Factors}

Social history was ascertained during the HCS baseline interview. At the HSSe interview, smoking status and weekly alcohol consumption were ascertained and details of all prescription and over-the-counter medications currently taken were coded according to the British National Formulary. Medication use across body wide systems (termed number of systems medicated) was used as a marker of comorbidity. We did not ascertain whether our participants were engaged in resistance or endurance-based activity in their leisure time.

\section{Statistical Methods}

Height and weight were highly correlated $(r=0.46, p<0.009$ for men; $r=0.43, p<0.001$ for women). To account for multi-collinearity, a sex-specific standardised residual of weight-adjusted-for-height was derived for inclusion with height in regression models. Registrar General's social class was coded from the 1990 Standard Occupational Classification (SOC90) unit group for occupation using computerassisted standard occupational coding [26]. Current social class was coded from current or most recent full-time occupation for men and women who never married, and from husband's occupation for ever-married women.

Data were described using summary statistics. Mean daily time spent in MVPA was skewed and included zeros and was therefore square-root transformed; the other physical activity measures and continuous outcome variables were normally distributed. Associations between physical activity measures were examined using Pearson correlations. Linear regression was used to examine the 
associations between each mean daily physical activity measure (acceleration, time in non-sedentary levels and time in MVPA levels) and the following outcomes: weight, BMI, total fat mass, ALM index, grip strength and walking speed. Poisson regression models with a robust variance estimator to yield relative risks were used for sarcopenia as the outcome variable. Gender-adjusted and fully adjusted models (accounting for gender, age, height, weight-forheight residual, smoking, alcohol and social class) were implemented. Gender-adjusted and fully adjusted models for ALM index and sarcopenia were adjusted for total fat mass and not for height or weight-for-height residual. Models for weight, BMI and total fat mass were not adjusted for any adiposity measures and models for BMI were also not adjusted for height. Sex-specific standard deviation (SD) scores were coded for physical activity measures and continuous outcomes in models. Due to the small number of men in the sample $(n=32)$, pooled gender-adjusted analyses were conducted. All data were analysed using Stata, release 14.2 (STATA Corp, College Station, TX, USA).

\section{Results}

\section{Participant Characteristics}

The average age at the time of wearing the accelerometer was 79 years. Median daily time spent at non-sedentary activity levels was 138 and 186 min among men and women, respectively. In contrast, the median daily time spent in MVPA was only $14.3 \mathrm{~min}$ for men and $9.5 \mathrm{~min}$ for women. Overall 5 (16.1\%) men and 21 (21.6\%) women had sarcopenia (Table 1).
Table 1 Participant characteristics

\begin{tabular}{|c|c|c|}
\hline Mean (SD) & $\operatorname{Men}(n=32)$ & Women $(n=99)$ \\
\hline Age (years) & $78.6(2.7)$ & $78.9(2.3)$ \\
\hline Height $(\mathrm{cm})$ & $172.4(6.1)$ & $159.4(5.9)$ \\
\hline Weight (kg) & $78.9(12.2)$ & $70.8(12.3)$ \\
\hline BMI $\left(\mathrm{kg} / \mathrm{m}^{2}\right)$ & $26.5(3.7)$ & $27.8(4.4)$ \\
\hline Total body fat mass $(\mathrm{kg})$ & $27.1(9)$ & $31.1(8.3)$ \\
\hline Fat mass index $\left(\mathrm{kg} / \mathrm{m}^{2}\right)$ & $9.1(3.0)$ & $12.2(3.2)$ \\
\hline Appendicular lean mass (kg) & $21.3(2.8)$ & $15.2(2.4)$ \\
\hline Appendicular lean mass index $\left(\mathrm{kg} / \mathrm{m}^{2}\right)$ & $7.2(0.9)$ & $6.0(0.8)$ \\
\hline Grip strength (kg) & $34.8(6.5)$ & $20.7(5.6)$ \\
\hline Walking speed (m/s) & $0.98(0.18)$ & $0.96(0.19)$ \\
\hline EWGSOP sarcopenia $^{a}$ & $5(16.1 \%)$ & $21(21.6 \%)$ \\
\hline Ever smoked $^{\mathrm{a}}$ & $14(43.8 \%)$ & $38(38.4 \%)$ \\
\hline Social class (manual) ${ }^{\mathrm{a}}$ & $13(43.3 \%)$ & $49(49.5 \%)$ \\
\hline Ever smoked ${ }^{\mathrm{b}}$ & $14(43.8 \%)$ & $38(38.4 \%)$ \\
\hline \multicolumn{3}{|l|}{ Alcohol consumption (units per week) ${ }^{\mathrm{a}}$} \\
\hline Very low $(<1)$ & $7(21.9 \%)$ & $55(55.6 \%)$ \\
\hline Low (1-10 M, 1-7 W) & $16(50 \%)$ & $32(32.3 \%)$ \\
\hline Moderate (11-21 M, 8-14 W) & $5(15.6 \%)$ & $10(10.1 \%)$ \\
\hline $\operatorname{High}(>21 \mathrm{M},>14 \mathrm{~W})$ & $4(12.5 \%)$ & $2(2 \%)$ \\
\hline Acceleration $(\mathrm{mg})^{+}$ & $23.9(7.6)$ & $25.5(6.8)$ \\
\hline Non-sedentary $(\mathrm{min} / \text { day })^{\mathrm{b}}$ & $137.8(81.7,217.2)$ & $186.0(122.1,240.4)$ \\
\hline MVPA (min/day) $)^{\mathrm{b}}$ & $14.3(1.8,30.2)$ & $9.5(2.1,18.6)$ \\
\hline \multicolumn{3}{|c|}{ Maximum number of missing observations was nine (total body fat, fat mass index and walking speed) } \\
\hline \multicolumn{3}{|c|}{ Manual social class: categories IIIM-V from 1990 OPCS Standard Occupational Classification } \\
\hline \multicolumn{3}{|c|}{$\begin{array}{l}\text { Three individuals could not walk without another person's help and four used a walking aid so their values } \\
\text { of walking speed were set to missing }\end{array}$} \\
\hline \multicolumn{3}{|c|}{$M$ men, $W$ women, $M V P A$ moderate-to-vigorous physical activity } \\
\hline \multicolumn{3}{|c|}{${ }^{+}$Average daily $(24 \mathrm{~h})$ acceleration for each participant } \\
\hline${ }^{\mathrm{a}} n(\%)$ & & \\
\hline
\end{tabular}




\section{Associations Between Objective Measures of Physical Activity and Body Composition and Sarcopenia}

Mean daily acceleration was strongly correlated with nonsedentary time $(r=0.92)$. Time spent in MVPA was correlated with daily acceleration $(r=0.73)$ and non-sedentary time ( $r=0.65)(p<0.05$ for all correlations). Relationships between physical activity measures and ALM index, grip strength and walking speed are presented in Table 2 as well as Fig. 2. Greater non-sedentary time was weakly associated $(p=0.07)$ with higher ALM index after adjustment for gender and total fat mass but this was attenuated by full adjustment. Greater level of daily acceleration and increased nonsedentary time were associated with faster walking speed in gender-adjusted and fully adjusted analyses. For example, a one SD increase in non-sedentary time was associated with an average increase in walking speed of 0.27 (95\% CI 0.08, $0.46)$ SDs in fully adjusted analyses. None of the physical activity measures were associated with grip strength. Higher physical activity according to each of the three measures was associated with reduced risk of sarcopenia after adjustment
Table 2 SD difference in ALM index, grip strength, walking speed and relative risks for sarcopenia per SD increase in the physical activity measures

\begin{tabular}{|c|c|c|c|c|c|}
\hline \multirow[t]{2}{*}{ Physical activity measure } & \multirow[t]{2}{*}{ Outcome } & \multicolumn{2}{|l|}{ Adjusted for gender } & \multicolumn{2}{|l|}{ Fully adjusted $^{\mathrm{a}}$} \\
\hline & & Estimate $(95 \% \mathrm{CI})$ & $p$ value & Estimate $(95 \% \mathrm{CI})$ & $p$ value \\
\hline \multirow[t]{4}{*}{ Acceleration } & ALM index & $0.15(-0.03,0.32)$ & 0.10 & $0.12(-0.07,0.30)$ & 0.21 \\
\hline & Grip strength & $0.11(-0.07,0.28)$ & 0.24 & $0.12(-0.08,0.31)$ & 0.23 \\
\hline & Walking speed & $0.26(0.08,0.44)$ & 0.01 & $0.25(0.05,0.45)$ & 0.02 \\
\hline & Sarcopenia & $0.67(0.47,0.95)$ & 0.03 & $0.65(0.43,0.99)$ & 0.05 \\
\hline \multirow[t]{4}{*}{ Time in non-sedentary levels } & ALM index & $0.16(-0.01,0.33)$ & 0.07 & $0.14(-0.04,0.31)$ & 0.13 \\
\hline & Grip strength & $0.15(-0.02,0.33)$ & 0.08 & $0.16(-0.03,0.34)$ & 0.09 \\
\hline & Walking speed & $0.29(0.12,0.47)$ & $<0.001$ & $0.27(0.08,0.46)$ & 0.01 \\
\hline & Sarcopenia & $0.66(0.45,0.96)$ & 0.03 & $0.67(0.44,1.01)$ & 0.06 \\
\hline \multirow[t]{4}{*}{ Time in MVPA levels } & ALM index & $0.06(-0.12,0.24)$ & 0.51 & $0.01(-0.18,0.20)$ & 0.93 \\
\hline & Grip strength & $0.10(-0.08,0.27)$ & 0.29 & $0.11(-0.09,0.31)$ & 0.27 \\
\hline & Walking speed & $0.19(0.01,0.37)$ & 0.04 & $0.16(-0.05,0.37)$ & 0.14 \\
\hline & Sarcopenia & $0.65(0.43,0.98)$ & 0.04 & $0.70(0.43,1.13)$ & 0.14 \\
\hline
\end{tabular}

For each participant, mean daily physical activity measures were derived $S D$ standard deviation, $A L M$ appendicular lean mass

Gender- and fully adjusted models for ALM index and sarcopenia were adjusted for total fat mass and not for height or weight-for-height residual

Estimates for sarcopenia are relative risks obtained from Poisson regression models with a robust variance estimator. All other estimates are regression coefficients obtained from linear regression models

${ }^{a}$ Adjusted for gender, age, height, weight-for-height residual, smoking history (ever vs. never), alcohol consumption, and social class (manual vs. non-manual)
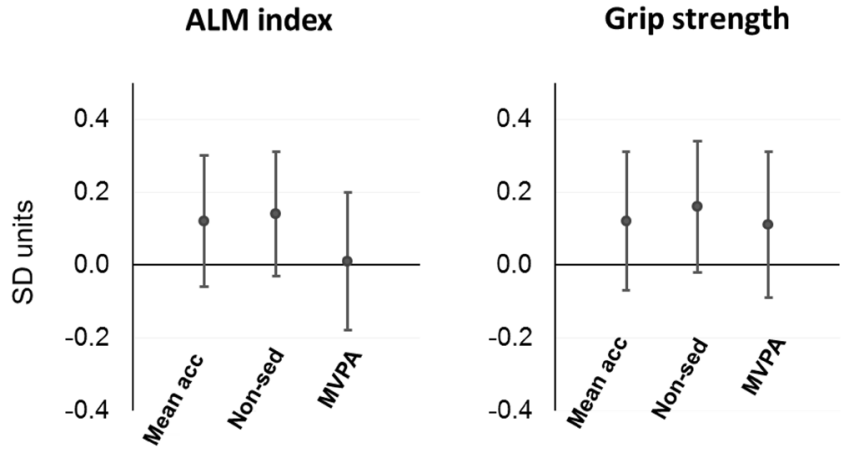

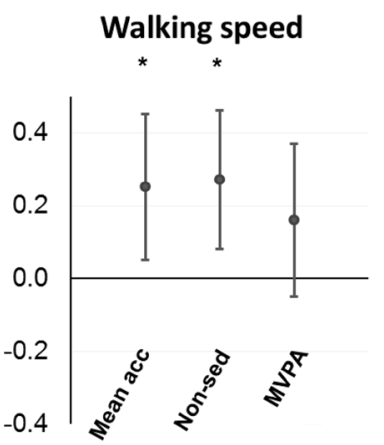

Fig. 2 SD difference in outcomes (95\% CI) per SD increase in physical activity measures (fully adjusted associations). Estimates are adjusted for gender, age, height, weight-for-height residual, smoking history (ever vs. never), alcohol consumption, and social class (manual vs. non-manual). ALM index was adjusted for total fat mass and not for height or weight-for-height residual. $S D$ standard deviation, ALM appendicular lean mass, Mean acc mean acceleration, Non-sed non-sedentary, MVPA moderate-to-vigorous physical activity. For each participant, mean daily physical activity measures were derived. $* p<0.05$ 
for gender and total fat mass $(p<0.05)$; associations regarding mean daily acceleration were robust in fully adjusted analyses $(p=0.047)$. Associations were not substantially altered when additionally adjusted for the number of systems medicated (data not shown).

\section{Associations Between Physical Activity Measures and Weight, BMI and Fat Mass}

Associations between physical activity measures and weight, BMI and fat mass are presented in Table 3. In genderadjusted and fully adjusted analyses, higher physical activity was associated with lower weight, BMI, and fat mass, regardless of the physical activity measure used.

\section{Discussion}

In this study of community-dwelling older men and women, we have shown that a higher level of objectively measured PA was associated with reduced adiposity, increased function (faster walking speed) and decreased risk of sarcopenia. PA was not significantly associated with muscle strength or ALM index.

Older men and women in this study only spent a median of 14 and 10 min a day engaging in moderate-to-vigorous physical activity, respectively, falling significantly short of the WHO's recommendation of at least $150 \mathrm{~min}$ of moderate-intensity aerobic physical activity throughout the week for a sustained health benefit [27]. Our results are in accordance with other studies which have shown that older adults engage in significantly fewer minutes of MVPA not only when compared with young adults, but also relative to recommended guidelines [28]. Previous studies of older people have also utilised the threshold of $100 \mathrm{mg}$ to identify MVPA ( $\geq 3$ METS) [22, 23]; however, it should be acknowledged that this threshold was not explicitly developed for older adults [29]. This may explain the low levels of MVPA that were apparent in our study. Importantly however, greater time spent at any non-sedentary level of PA may confer health benefits [30, 31]. For example, a recent systematic review and meta-analysis by Hupin et al. reported that MVPA in adults, even below current recommended levels, conferred a lower mortality risk [32].

Our results regarding associations between PA and adiposity are consistent with the literature. Time spent in nonsedentary activity as well as MVPA has been shown to be associated with lower adiposity and lower BMI in several population-based studies [4, 33, 34] and a systematic review by Fuzeki et al. concluded that engagement in light PA was associated with less risk of developing obesity [35].

Our results regarding the positive associations $(p<0.07)$ observed between PA and ALM index are also in broad agreement with those reported in the literature. For example, Foong et al. showed that among community-dwelling older men and women, light as well as higher intensity levels of PA were positively associated with higher lean mass percentage whilst sedentary activity had the opposite effect [11]. In studies of older Japanese men, moderate or vigorous physical activity ( $\geq 3$ metabolic equivalents [METS]) was associated with lower lean mass index [36], a finding not replicated in our study (although the majority of our sample were female).

We did not see an association between PA and grip strength in our study. Although Gerdhem et al. found no association between accelerometer-based PA and knee

Table 3 SD difference in weight, BMI and fat mass per SD increase in the physical activity measures

\begin{tabular}{|c|c|c|c|c|c|}
\hline \multirow[t]{2}{*}{ Physical activity measure } & \multirow[t]{2}{*}{ Outcome } & \multicolumn{2}{|l|}{ Gender-adjusted } & \multicolumn{2}{|l|}{ Fully adjusted $^{\mathrm{a}}$} \\
\hline & & Estimate (95\% CI) & $p$ value & Estimate $(95 \% \mathrm{CI})$ & $p$ value \\
\hline \multirow[t]{3}{*}{ Acceleration } & Weight & $-0.43(-0.58,-0.27)$ & $<0.001$ & $-0.40(-0.55,-0.26)$ & $<0.001$ \\
\hline & BMI & $-0.46(-0.61,-0.30)$ & $<0.001$ & $-0.45(-0.61,-0.30)$ & $<0.001$ \\
\hline & Fat mass & $-0.50(-0.66,-0.34)$ & $<0.001$ & $-0.49(-0.64,-0.33)$ & $<0.001$ \\
\hline \multirow[t]{3}{*}{ Time in non-sedentary levels } & Weight & $-0.35(-0.51,-0.19)$ & $<0.001$ & $-0.33(-0.48,-0.18)$ & $<0.001$ \\
\hline & BMI & $-0.39(-0.55,-0.23)$ & $<0.001$ & $-0.37(-0.54,-0.21)$ & $<0.001$ \\
\hline & Fat mass & $-0.46(-0.62,-0.30)$ & $<0.001$ & $-0.44(-0.59,-0.28)$ & $<0.001$ \\
\hline \multirow[t]{3}{*}{ Time in MVPA levels } & Weight & $-0.43(-0.58,-0.27)$ & $<0.001$ & $-0.41(-0.56,-0.26)$ & $<0.001$ \\
\hline & BMI & $-0.42(-0.58,-0.26)$ & $<0.001$ & $-0.45(-0.61,-0.29)$ & $<0.001$ \\
\hline & Fat mass & $-0.49(-0.64,-0.33)$ & $<0.001$ & $-0.51(-0.67,-0.35)$ & $<0.001$ \\
\hline
\end{tabular}

For each participant, mean daily physical activity measures were derived

Models for BMI were not adjusted for height

Estimates are regression coefficients obtained from linear regression models

$S D$ standard deviation

${ }^{a}$ Adjusted for gender, age, height, smoking history (ever vs. never), alcohol consumption, and social class (manual vs. non-manual) 
muscle strength [37], the large cross-sectional study of older men by Aggio et al. identified positive associations between PA and both grip strength and physical performance [4]. In addition, a large population-based cross-sectional study identified associations between light, moderate and vigorous accelerometer-based physical activity and stronger leg and knee extension strength [11]. Furthermore, sedentary behaviour ascertained by questionnaire analysis was associated with lower grip strength in a study by Hamer and Stamatakis [38]. Other studies have also reported positive associations between objective measures of PA and grip strength [12, 17]. It is possible that HSSe participants may not have been taking part in activities that benefit upper extremity strength. This may provide an explanation for our results [39].

Our finding that increased non-sedentary time was associated with faster gait speed is consistent with previous studies that have reported associations between higher levels of objectively measured light or moderate-to-vigorous PA and better physical performance [40,41]. Our results suggest an association between higher levels of PA and a lower risk of sarcopenia. In support of our findings, associations between PA and a lower risk of acquiring sarcopenia were confirmed in a recent meta-analysis [18]. To our knowledge, only one previous study has reported an association between higher MVPA and reduced risk of developing severe sarcopenia according to the EWGSOP diagnostic algorithm [4].

Our study has some limitations. First, a healthy responder bias has been observed in HCS and is also evident in HSSe. However, as our analyses were internal, unless there was a systematic difference in the observations of interest among our study participants and those who were invited to take part in the study but did not, no major bias should have occurred. Second, we have a relatively small sample size with no ethnic diversity but this was the largest available; higher attrition from the target sample was expected due to the commitment required from participants to wear the device for 7 days. Third, a cross-sectional study design precludes any judgment regarding causality. Fourth, participants wore the accelerometer during different months of the year which may have influenced their physical activity levels.

Our study also has many strengths. First, the HSSe has a comprehensive set of muscle outcomes (muscle mass and body composition, strength and function) making this relatively unusual among other studies. The study was conducted according to strict protocols by an experienced multi-disciplinary research team. Second, we have obtained objective measures of PA. The GENEActiv and other wearable accelerometers accurately discriminate between different PA intensities and are acceptable and feasible to use in cohorts of older people as they are non-intrusive, waterproof, robust and importantly store substantial amounts of data [42]. In addition, the high criterion validity of this device in relation to energy expenditure (left wrist, $r=0.86$; right wrist, $r=0.83$ ) and high reliability (intra-individual variance $1.4 \%$, inter-individual variance $2.1 \%$ ) have been reported previously [43]. A minimum of 6 days including weekends is recommended to capture habitual PA which was within the scope of our fieldwork. Finally, we implemented a robust methodology for data extraction and summary of the data recorded by the GENEactiv device. Reference details [44-49] are given in supplementary material.

In conclusion, we have shown that higher levels of objectively measured PA are associated with reduced adiposity, increased muscle mass, function and decreased risk of sarcopenia. Our results contribute to better understanding of the consequences of different levels of PA and sedentary behaviour among older people. These results suggest that incremental elevations in habitual physical activity in older people may help to decelerate age-related declines in musculoskeletal fitness.

Acknowledgements We would like to thank the study participants as well as the HSS research nurses who greatly contributed to the success of the study: Norma Diaper, Sanchia Triggs, Andrea Staniford and Gemma Rood. This work was supported by the NIHR Southampton Biomedical Research Centre, Nutrition, the MRC Lifecourse Epidemiology Unit and the University of Southampton. RD is supported by an NIHR Clinical Lecturer training scheme, AMB is supported by the NIHR Academic Training Scheme; AMB and HCR are also supported by the NIHR CLAHRC: Wessex. AAS is supported by the NIHR Newcastle Biomedical Research Centre. HPP is supported by the National Institute for Health Research through the NIHR Southampton Biomedical Research Centre. This report is independent research and the views expressed in this publication are those of the authors and not necessarily those of the NHS, the NIHR or the Department of Health. The funding bodies had no role in any of the design, collection and analysis, interpretation of data, writing of the manuscript or decision to submit for publication.

Author Contributions AAS, HCR, CC and HPP set up the HSSe study. RD, SS, AMB and HPP coordinated and conducted the fieldwork. LW, RD and HES provided statistical support. LW, HES and HPP wrote the first draft. All authors read and approved the final version of this manuscript.

\section{Compliance with Ethical Standards}

Conflict of interest Leo D. Westbury, Richard M. Dodds, Holly E. Syddall, Alicja M. Baczynska, Sarah C. Shaw, Elaine M. Dennison, Helen C. Roberts, Avan Aihie Sayer, Cyrus Cooper and Harnish P. Patel confirm that they have no conflict of interest related to this study.

Human and Animal Rights and Informed Consent All procedures on participants were performed in accordance with ethical standards stipulated by the Hertfordshire Research Ethics Committee. Each participant gave written informed consent.

Open Access This article is distributed under the terms of the Creative Commons Attribution 4.0 International License (http://creativeco mmons.org/licenses/by/4.0/), which permits unrestricted use, distribution, and reproduction in any medium, provided you give appropriate credit to the original author(s) and the source, provide a link to the Creative Commons license, and indicate if changes were made. 


\section{References}

1. Cooper R, Kuh D, Hardy R (2010) Objectively measured physical capability levels and mortality: systematic review and metaanalysis. BMJ 341:c4467

2. Cruz-Jentoft AJ, Baeyens JP, Bauer JM, Boirie Y, Cederholm T, Landi F et al (2010) Sarcopenia: European consensus on definition and diagnosis: report of the European Working Group on Sarcopenia in Older People. Age Ageing 39(4):412-423

3. Caspersen CJ, Powell KE, Christenson GM (1985) Physical activity, exercise, and physical fitness: definitions and distinctions for health-related research. Public Health Rep 100(2):126-131

4. Aggio DA, Sartini C, Papacosta O, Lennon LT, Ash S, Whincup PH et al (2016) Cross-sectional associations of objectively measured physical activity and sedentary time with sarcopenia and sarcopenic obesity in older men. Prev Med 91:264-272

5. Cauley JA, Harrison SL, Cawthon PM, Ensrud KE, Danielson ME, Orwoll E et al (2013) Objective measures of physical activity, fractures and falls: the osteoporotic fractures in men study. J Am Geriatr Soc 61(7):1080-1088

6. Moayyeri A (2008) The association between physical activity and osteoporotic fractures: a review of the evidence and implications for future research. Ann Epidemiol 18(11):827-835

7. Awick EA, Ehlers DK, Aguinaga S, Daugherty AM, Kramer AF, McAuley E (2017) Effects of a randomized exercise trial on physical activity, psychological distress and quality of life in older adults. Gen Hosp Psychiatry 49:44-50

8. Ford ES, Caspersen CJ (2012) Sedentary behaviour and cardiovascular disease: a review of prospective studies. Int J Epidemiol 41(5):1338-1353

9. Ryan DJ, Stebbings GK, Onambele GL (2015) The emergence of sedentary behaviour physiology and its effects on the cardiometabolic profile in young and older adults. Age (Dordrecht Netherlands) 37(5):89

10. Prince SA, Adamo KB, Hamel ME, Hardt J, Connor Gorber S, Tremblay M (2008) A comparison of direct versus self-report measures for assessing physical activity in adults: a systematic review. Int J Behav Nutr Phys Act 5:56

11. Foong YC, Chherawala N, Aitken D, Scott D, Winzenberg T, Jones G (2016) Accelerometer-determined physical activity, muscle mass, and leg strength in community-dwelling older adults. J Cachexia Sarcopenia Muscle 7(3):275-283

12. Bann D, Hire D, Manini T, Cooper R, Botoseneanu A, McDermott MM et al (2015) Light Intensity physical activity and sedentary behavior in relation to body mass index and grip strength in older adults: cross-sectional findings from the Lifestyle Interventions and Independence for Elders (LIFE) study. PLoS ONE 10(2):e0116058

13. de Vries NM, van Ravensberg CD, Hobbelen JS, Olde Rikkert MG, Staal JB, Nijhuis-van der Sanden MW (2012) Effects of physical exercise therapy on mobility, physical functioning, physical activity and quality of life in community-dwelling older adults with impaired mobility, physical disability and/or multimorbidity: a meta-analysis. Ageing Res Rev 11(1):136-149

14. Park S, Thogersen-Ntoumani C, Ntoumanis N, Stenling A, Fenton SA, Veldhuijzen van Zanten JJ (2017) Profiles of physical function, physical activity, and sedentary behavior and their associations with mental health in residents of assisted living facilities. Appl Psychol Health Well Being 9(1):60-80

15. Rojer AGM, Reijnierse EM, Trappenburg MC, van Lummel RC, Niessen M, van Schooten KS et al (2017) Instrumented assessment of physical activity is associated with muscle function but not with muscle mass in a general population. J Aging Health. https://doi.org/10.1177/0898264317721554
16. Ryu M, Jo J, Lee Y, Chung YS, Kim KM, Baek WC (2013) Association of physical activity with sarcopenia and sarcopenic obesity in community-dwelling older adults: the Fourth Korea National Health and Nutrition Examination Survey. Age Ageing 42(6):734-740

17. Corcoran MP, Chui KK, White DK, Reid KF, Kirn D, Nelson ME et al (2016) Accelerometer assessment of physical activity and its association with physical function in older adults residing at assisted care facilities. J Nutr Health Aging 20(7):752-758

18. Steffl M, Bohannon RW, Sontakova L, Tufano JJ, Shiells K, Holmerova I (2017) Relationship between sarcopenia and physical activity in older people: a systematic review and meta-analysis. Clin Interv Aging 12:835-845

19. Patel HP, Syddall HE, Martin HJ, Stewart CE, Cooper C, Sayer AA (2010) Hertfordshire sarcopenia study: design and methods. BMC Geriatr 10:43

20. Syddall HE, Sayer AA, Dennison EM, Martin HJ, Barker DJ, Cooper C (2005) Cohort profile: the Hertfordshire cohort study. IntJ Epidemiol 34(6): 1234-1242

21. van Hees VT, Gorzelniak L, Dean Leon EC, Eder M, Pias M, Taherian $\mathrm{S}$ et al (2013) Separating movement and gravity components in an acceleration signal and implications for the assessment of human daily physical activity. PLoS One 8(4):e61691

22. Menai M, Van Hees VT, Elbaz A, Kivimaki M, Singh-Manoux A, Sabia S (2017) Accelerometer assessed moderate-to-vigorous physical activity and successful ageing: results from the Whitehall II study. Sci Rep 7:45772

23. Sabia S, Cogranne P, van Hees VT, Bell JA, Elbaz A, Kivimaki $M$ et al (2015) Physical activity and adiposity markers at older ages: accelerometer vs. questionnaire data. J Am Med Dir Assoc 16(5):438e 7-438e 13

24. Charman SJ, van Hees VT, Quinn L, Dunford JR, Bawamia B, Veerasamy $M$ et al (2016) The effect of percutaneous coronary intervention on habitual physical activity in older patients. BMC Cardiovasc Disord 16(1):248

25. Cruz-Jentoft AJ, Landi F, Schneider SM, Zuniga C, Arai H, Boirie $Y$ et al (2014) Prevalence of and interventions for sarcopenia in ageing adults: a systematic review. Report of the International Sarcopenia Initiative (EWGSOP and IWGS). Age Ageing 43(6):748-759

26. Elias P, Halstead K, Prandy K (1993) Computer assisted standard occupational coding. Standard Occupational Classification, London

27. World Health Organization (2010) Global recommendations on physical activity for health. World Health Organization, Geneva

28. Davis MG, Fox KR (2007) Physical activity patterns assessed by accelerometry in older people. Eur J Appl Physiol 100(5):581-589

29. Hildebrand M, Van Hees VT, Hansen BH, Ekelund U (2014) Agegroup comparability of raw accelerometer output from wrist-and hip-worn monitors. Med Sci Sports Exerc 46(9):1816-1824

30. Loprinzi PD (2017) Light-intensity physical activity and all-cause mortality. Am J Health Promot 31(4):340-342

31. Warburton DER, Bredin SSD (2017) Health benefits of physical activity: a systematic review of current systematic reviews. Curr Opin Cardiol 32:541-556

32. Hupin D, Roche F, Gremeaux V, Chatard JC, Oriol M, Gaspoz JM et al (2015) Even a low-dose of moderate-to-vigorous physical activity reduces mortality by $22 \%$ in adults aged $\geq 60$ years: a systematic review and meta-analysis. Br J Sports Med 49(19):1262-1267

33. Fortune E, Mundell B, Amin S, Kaufman K (2017) A pilot study of physical activity and sedentary behavior distribution patterns in older women. Gait Posture 57:74-79

34. Healy GN, Wijndaele K, Dunstan DW, Shaw JE, Salmon J, Zimmet PZ et al (2008) Objectively measured sedentary time, physical 
activity, and metabolic risk: the Australian Diabetes, Obesity and Lifestyle Study (AusDiab). Diabetes Care 31(2):369-371

35. Fuzeki E, Engeroff T, Banzer W (2017) Health benefits of lightintensity physical activity: a systematic review of accelerometer data of the national health and nutrition examination survey (NHANES). Sports Med 47:1769-1793

36. Shephard RJ, Park H, Park S, Aoyagi Y (2013) Objectively measured physical activity and progressive loss of lean tissue in older Japanese adults: longitudinal data from the Nakanojo study. J Am Geriatr Soc 61(11):1887-1893

37. Gerdhem P, Dencker M, Ringsberg K, Akesson K (2008) Accelerometer-measured daily physical activity among octogenerians: results and associations to other indices of physical performance and bone density. Eur J Appl Physiol 102(2):173-180

38. Hamer M, Stamatakis E (2013) Screen-based sedentary behavior, physical activity, and muscle strength in the English longitudinal study of ageing. PLoS ONE 8(6):e66222

39. van Lummel RC, Walgaard S, Pijnappels M, Elders PJ, GarciaAymerich J, van Dieen JH et al (2015) Physical performance and physical activity in older adults: associated but separate domains of physical function in old age. PLoS ONE 10(12):e0144048

40. Matthews CE, Keadle SK, Troiano RP, Kahle L, Koster A, Brychta $\mathrm{R}$ et al (2016) Accelerometer-measured dose-response for physical activity, sedentary time, and mortality in US adults. Am J Clini Nutr 104(5):1424-1432

41. Trayers T, Lawlor DA, Fox KR, Coulson J, Davis M, Stathi A et al (2014) Associations of objectively measured physical activity with lower limb function in older men and women: findings from the Older People and Active Living (OPAL) study. J Aging Phys Act 22(1):34-43

42. Garatachea N, Torres Luque G, Gonzalez Gallego J (2010) Physical activity and energy expenditure measurements using accelerometers in older adults. Nutr Hosp 25(2):224-230
43. Esliger DW, Rowlands AV, Hurst TL, Catt M, Murray P, Eston RG (2011) Validation of the GENEA accelerometer. Med Sci Sports Exerc 43:1085-1093

44. Zhang S, Murray P, Zillmer R, Eston RG, Catt M, Rowlands AV (2012) Activity classification using the GENEA: optimum sampling frequency and number of axes. Med Sci Sports Exerc 44(11):2228-2234

45. van Hees VT, Fang Z, Langford J, Assah F, Mohammad A, da Silva IC et al (2014) Autocalibration of accelerometer data for free-living physical activity assessment using local gravity and temperature: an evaluation on four continents. J Appl Physiol 117(7):738-744

46. Van Hees VT, Gorzelniak L, Leon ECD, Eder M, Pias M, Taherian $\mathrm{S}$ et al (2013) Separating movement and gravity components in an acceleration signal and implications for the assessment of human daily physical activity. PLoS ONE 8(4):e61691

47. da Silva IC, van Hees VT, Ramires VV, Knuth AG, Bielemann RM, Ekelund U et al (2014) Physical activity levels in three Brazilian birth cohorts as assessed with raw triaxial wrist accelerometry. Int J Epidemiol 43(6):1959-1968

48. Sabia S, van Hees VT, Shipley MJ, Trenell MI, Hagger-Johnson G, Elbaz A et al (2014) Association between questionnaire-and accelerometer-assessed physical activity: the role of sociodemographic factors. Am J Epidemiol 179(6):781-790

49. van Hees VT, Renström F, Wright A, Gradmark A, Catt M, Chen $\mathrm{KY}$ et al (2011) Estimation of daily energy expenditure in pregnant and non-pregnant women using a wrist-worn tri-axial accelerometer. PLoS ONE 6(7):e22922

\section{Affiliations}

\section{Leo D. Westbury ${ }^{1} \cdot$ Richard M. Dodds $^{2} \cdot$ Holly E. Syddall $^{1} \cdot$ Alicja M. Baczynska ${ }^{2,3,4} \cdot$ Sarah C. Shaw $^{1}$. Elaine M. Dennison ${ }^{1} \cdot$ Helen C. Roberts ${ }^{2,3,4} \cdot$ Avan Aihie Sayer $^{2,5,6} \cdot$ Cyrus Cooper $^{1,7} \cdot$ Harnish P. Patel $^{1,2,3}$ (D)}

\author{
Leo D. Westbury \\ 1w@mrc.soton.ac.uk \\ Richard M. Dodds \\ r.dodds@soton.ac.uk \\ Holly E. Syddall \\ hes@mrc.soton.ac.uk \\ Alicja M. Baczynska \\ a.baczynska@yahoo.com \\ Sarah C. Shaw \\ ss@mrc.soton.ac.uk \\ Elaine M. Dennison \\ emd@mrc.soton.ac.uk \\ Helen C. Roberts \\ h.c.roberts@soton.ac.uk \\ Avan Aihie Sayer \\ avan.sayer@newcastle.ac.uk \\ Cyrus Cooper \\ cc@mrc.soton.ac.uk
}

1 MRC Lifecourse Epidemiology Unit, University Hospital Southampton, Tremona Road, Southampton SO16 6YD, UK

2 Academic Geriatric Medicine, University of Southampton, Southampton, UK

3 National Institute for Health Research Southampton, Biomedical Research Centre, University of Southampton and University Hospital Southampton NHS Foundation Trust, Southampton, UK

4 NIHR Collaboration for Leadership in Applied Health Research and Care: Wessex, University of Southampton, Southampton, UK

5 AGE Research Group, Institute of Neuroscience, Newcastle, $\mathrm{UK}$

6 NIHR Newcastle Biomedical Research Centre, Newcastle University and Newcastle Upon Tyne Hospitals NHS Foundation Trust, Newcastle, UK

7 National Institute for Health Research Musculoskeletal Biomedical Research Unit, University of Oxford, Oxford, UK 